\title{
Effect of Young Maternal Age on Obstetric and Perinatal Outcomes: Results from the Tertiary Center in Turkey
}

\author{
Oya Demirci, Ertuğrul Yılmaz, Özgür Tosun, Pınar Kumru, Arzu Arınkan, Didar Mahmutoğlu, \\ Selçuk Selçuk, Zehra Nihal Dolgun, Resul Arısoy, Emre Erdoğdu, Nazan Tarhan
}

Department of Perinatology, Zeynep Kamil Gynecologic and Pediatric Training and Research Hospital, İstanbul, Turkey

\begin{abstract}
Background: Young maternal age is variously defined in studies of its effect on obstetrics and perinatal outcomes. Also, pregnancy has been reported as the leading cause of death in adolescent girls in low- and middle-income countries.
\end{abstract}

Aims: The aim of the study was to evaluate whether young maternal age was associated with an increased risk of obstetrics and perinatal adverse outcomes.

Study Design: Case-control study.

Methods: This case-control study was derived from a database of the medical records between January 2008 and December 2012. In the present study, 1374 teenage pregnancy and 1294 adult pregnancy cases were included. After restriction of analyses to singleton primiparous women, 1282 teenage pregnancy and 735 adult pregnancy cases were analyzed. Maternal age was separated into three groups: 15 and less, 16-19, and 20-34 years. Adjusted odds ratios (ORs) were derived through logistic regression models for the potential confounding factors.

Results: Adolescents aged 15 years and younger had higher risks of preterm delivery, early preterm delivery, intrauterine fetal death and neonatal death compared with women aged 20 to 34 years after adjustment for confounding factors. In addition, both groups of adolescents had higher risks for anemia and episiotomy and lower risk of cesarean delivery. The rates of preeclampsia, gestational diabetes, chronic diseases, intrauterine growth restriction (IUGR) were higher in the adult group.

Conclusion: Younger maternal age was correlated with increased risks of preterm delivery, fetal and neonatal death and anemia.

Keywords: Adolescent pregnancy, perinatal mortality, preterm delivery
Adolescent pregnancy is defined as pregnancy in girls aged less than 20 years. It is estimated that 16 million 15-19 yearold women give birth every year, accounting for approximately $11 \%$ of all births worldwide (1). In low- and middle-income countries, pregnancy has been reported as the main factor of death in adolescent girls (1). Young maternal age has usually been considered a high risk in relation to adverse pregnancy outcomes (1-16). Possible explanations for adverse pregnancy outcomes have been thought to be their biological immaturity or poor social, economic and behavioral factors such as smok- ing, alcohol/substance abuse, malnutrition and inadequate prenatal care (17-22). However, the previous studies had conflicting findings regarding whether the effect of young maternal age on adverse pregnancy outcomes were caused by their biological immaturity or poor social, economic and behavioral factors (17-22).

The aim of the present study was to investigate whether there is an association between young maternal age and poor maternal and perinatal outcomes independent of possible confounding factors. 


\section{MATERIALS AND METHODS}

This retrospective study was performed on the medical data records between January 2008 and December 2012. The local ethics committee approved this study. At the beginning, 1374 teenage pregnancy and 1294 adult pregnancy cases were recruited for this retrospective study. After the restriction of analyses to singleton primiparous women and the exclusion of cases with multiple pregnancies, congenital malformations and chromosomal abnormalities, 1282 teenage pregnancy and 735 adult pregnancy cases were analyzed. The present study was designed to compare obstetric and perinatal outcomes between adolescents aged 19 and younger and adults aged 20-34 years. Adolescents younger than 16 years, which is defined as low gynecological age, have been shown to be at a higher risk of adverse pregnancy outcomes (17). Therefore, maternal age was categorized into three groups: 15 years and younger, 1619 years and $20-34$ years. Here, 35 year-old and above women were excluded due to the high adverse outcome risks. Also, adolescent pregnancies related to sexual abuse were excluded.

The number of completed weeks' gestation between the first day of the last menstrual period and delivery date was defined as gestational age at birth. The maternal education level was classified as primary school or less, secondary school, high school or more. Cigarette smoking was recorded as nonsmoker and smoker. Number of prenatal visits was categorized as less than four or four and more.

Perinatal outcomes examined were very low birth weight (VLBW) (birth weight $\leq 1500$ g); low birth weight (LBW) (birth weight $\leq 2500 \mathrm{~g}$ or less); macrosomia (birth weight $\geq$ $4000 \mathrm{~g}$ ); IUGR (birth weight $<10$ th percentile using previously published curves standardized for gestational age(23)); preterm delivery ( $<37$ completed weeks); early preterm delivery ( $<34$ completed weeks); intrauterine fetal death (delivery of a dead infant after 22 week' gestation); neonatal death (during the first 7 days of life); low Apgar score at 5 minutes $(<7)$ and admission to neonatal intensive care unit (NICU).

The International Classification Disease (ICD) was used to classify adverse maternal outcomes such as anemia throughout pregnancy (hemoglobin concentration $<10 \mathrm{~g} / \mathrm{dl}$ ), pre-eclampsia (hypertension $\geq 140 / 90 \mathrm{mmHg}$ and proteinuria $\geq 300 \mathrm{mg} /$ day in previously normotensive women) and eclamptic convulsion, third trimester bleeding including placenta previa and placental abruption, premature rupture of membrane (PROM), gestational diabetes, urinary tract infection, cesarean delivery, episiotomy, laseration, postpartum hemorrhage, puerperal endometritis. Cephalopelvic disproportion (CPD) as the indication for cesarean delivery included dystocia and failure to progress during delivery.

The Statistical Package for Social Sciences (SPSS Inc; version 11.5, Chicago, IL, USA) was used for statistical analysis.
Comparison of variables was analyzed using the Chi-square test. To detect whether they were normally distributed, the variables were analyzed using visual (histograms, probability plots) and statistical methods (Kolmogorov-Smirnov Test). Descriptive analyses were presented using medians and minmax for the non-normally distributed. The Kruskal-Wallis test were used to compare parameters which were not normally distributed. A p value of 0.05 was considered statistically significant. The Mann-Whitney $U$ test analyzed the pairwise differences using Bonferroni correction to adjust for multiple comparison. Adjusted odds ratios (ORs) were calculated by means of logistic regression models. The calculations were adjusted for the following possible confounding factors: mother's education, smoking, numbers of visits, chronic disease and anemia. Also, some parameters were additionally adjusted for preeclampsia, intrauterine growth restriction, lower urinary tract infection, premature rupture of membrane, preterm delivery and low birth weight depending on relationship status.

\section{RESULTS}

Throughout the study period, a total of 56,421 infants were born in our hospital. Overall, 1374 (2.4\%) infants were born to adolescents aged 19 years and younger. In the adolescent age group, 1282 infants were born to primiparous mothers. Within the primiparous mother group, $6.6 \%$ (85) infants were born to those aged 15 years and younger and $93.4 \%$ (1197) to those aged 16-19 years. At the beginning, 1294 adult pregnancy cases were recruited for the control group. After the restriction of analyses to singleton primiparous women, 735 adult pregnancies were analyzed. Tables 1 and 2 indicate the maternal demographic and obstetric characteristics of the study group. The youngest adolescents ( $<16$ years) had the highest preterm ( $<37$ weeks ) and early preterm labor $(<34$ weeks) rates, the highest intrauterine fetal death and neonatal death rate, the lowest birthweight and an Apgar score below 7 at 5 minutes, whereas the these parameters for older adolescents were similar to those of adult women. Compared with mothers aged 20 to 34 years, adolescent mothers had a higher incidence of prenatal anemia, lower educational level, lower number of prenatal visits, lower gestational age at birth, lower incidence of cesarean delivery, and higher incidence of episiotomy. The rates of preeclampsia, gestational diabetes, chronic diseases and intrauterine growth restriction were higher in the adult group. Also, CPD as an indication of cesarean delivery was found to be higher in the adult group.

In Table 3, adjusted ORs for the association between maternal age, and adverse maternal and perinatal outcomes are 
TABLE 1. Characteristics of the study population and maternal outcomes

\begin{tabular}{|c|c|c|c|c|}
\hline \multirow[b]{2}{*}{ Characteristics } & \multicolumn{3}{|c|}{ Maternal age (years) } & \multirow[b]{2}{*}{$\mathrm{p}$} \\
\hline & $\begin{array}{l}\leq 15 \\
\text { n: } 85\end{array}$ & $\begin{array}{c}16-19 \\
\text { n: } 1197\end{array}$ & $\begin{array}{l}20-34 \\
\text { n: } 735\end{array}$ & \\
\hline Maternal age & $14.63 \pm 0.65$ & $17.27 \pm 0.74$ & $23.01 \pm 4.57$ & \\
\hline \multicolumn{5}{|l|}{ Education level n (\%) } \\
\hline Primary school or less & $19(22.4 \%)$ & $202(16.9 \%)$ & $110(15 \%)$ & \multirow[t]{3}{*}{0.0001} \\
\hline Secondary school & $62(72.9 \%)$ & $932(77.9 \%)$ & $518(70.5 \%)$ & \\
\hline High school & $4(4.7 \%)$ & $63(5.3 \%)$ & $107(14.5 \%)$ & \\
\hline Cigarette smoking n (\%) & $4(4.7 \%)$ & $55(4.6 \%)$ & $31(4.2 \%)$ & NS \\
\hline \multicolumn{5}{|l|}{ Number of prenatal visit $\mathrm{n}(\%)$} \\
\hline$<4$ times & $71(83.5 \%)$ & $958(80 \%)$ & $414(56.3 \%)$ & \multirow{2}{*}{0.0001} \\
\hline$\geq 4$ times & $14(16.5 \%)$ & $239(20 \%)$ & $321(43.7 \%)$ & \\
\hline Chronic disease n (\%) & $1(1.2 \%)$ & $7(0.6 \%)$ & $15(2 \%)$ & 0.014 \\
\hline Anemia n (\%) & $14(16.5 \%)$ & $154(12.9 \%)$ & $75(10.2 \%)$ & 0.040 \\
\hline Gestational diabetes n (\%) & 0 & $2(0.2 \%)$ & $24(3.3 \%)$ & 0.0001 \\
\hline Preeclampsia n (\%) & $4(4.7 \%)$ & $45(3.8 \%)$ & $64(8.7 \%)$ & 0.0001 \\
\hline Eclampsia n (\%) & 0 & $2(0.2 \%)$ & $1(0.1 \%)$ & NS \\
\hline Urinary infection $\mathrm{n}(\%)$ & $12(14.1 \%)$ & $83(6.9 \%)$ & $72(9.8 \%)$ & 0.012 \\
\hline Placenta previa n $(\%)$ & 0 & $1(0.1 \%)$ & $6(0.8 \%)$ & NS \\
\hline Abruptio placenta $\mathrm{n}(\%)$ & $1(1.2 \%)$ & $9(0.8 \%)$ & $4(0.5 \%)$ & NS \\
\hline Chorioamnionitis n (\%) & 0 & $2(0.2 \%)$ & $4(0.5 \%)$ & NS \\
\hline Endometritis n (\%) & $1(1.2 \%)$ & $3(0.3 \%)$ & $6(0.8 \%)$ & NS \\
\hline Post-partum hemorrhage n (\%) & $3(3.5 \%)$ & $19(1.6 \%)$ & $22(3 \%)$ & NS \\
\hline Episiotomy n (\%) & $66(91.7 \%)$ & $866(90.6 \%)$ & $438(79.5)$ & 0.0001 \\
\hline Laseration n (\%) & $1(1.2 \%)$ & $24(2.5 \%)$ & $19(3.4 \%)$ & NS \\
\hline \multicolumn{5}{|l|}{ Mode of labor n (\%) } \\
\hline Vaginal delivery & $72(84.7 \%)$ & $956(79.9 \%)$ & $551(75 \%)$ & \multirow{2}{*}{0.014} \\
\hline Cesarean section & $13(15.3 \%)$ & $241(20.1 \%)$ & $184(25 \%)$ & \\
\hline
\end{tabular}

$\mathrm{N}$ : non-significant

demonstrated. Younger adolescents showed higher preterm delivery risks and early preterm delivery adjusted for education level, the number of prenatal visits, smoking, chronic diseases, low urinary tract infection, preterm rupture of membrane, preeclampsia and intrauterine growth restriction compared with adults aged 20-34 years. Infants born to mothers aged 15 years or younger exhibited higher risks of intrauterine fetal death and neonatal death than infants of mothers aged 2034 years after adjusting for level of education, prenatal visit numbers, smoking, chronic diseases, preeclampsia and intrauterine growth restriction. Adolescents aged 16-19 years had lower risks of LBW, IUGR, preeclampsia, gestational diabetes and PROM in comparison to adults. Our study group did not have maternal mortality. The adolescent mothers had a higher
TABLE 2. Association between perinatal outcomes and maternal age

\begin{tabular}{lcccc}
\hline & \multicolumn{3}{c}{ Maternal age (years) } \\
\cline { 2 - 4 } Variables & $\leq 15$ & $16-19$ & $20-34$ & $\mathrm{p}$ \\
\hline $\begin{array}{l}\text { Gestational age (weeks) } \\
\text { (mean } \pm \text { SD) }\end{array}$ & $36.64 \pm 3.61$ & $38.07 \pm 3.26$ & $38.26 \pm 2.77$ & 0.0001 \\
Preterm delivery & $36(42.4 \%)$ & $263(22 \%)$ & $147(20 \%)$ & 0.0001 \\
$\begin{array}{l}\text { Early preterm delivery } \\
(<34 \text { weeks) }\end{array}$ & $18(21.2 \%)$ & $120(10 \%)$ & $73(9.9 \%)$ & 0.004
\end{tabular}

Birth weight (gram) $\quad 2799.78 \pm 791.093098 .39 \pm 576.63 \quad 3042.28 \pm 601.74 \quad 0.002$ $($ mean $\pm \mathrm{SD})$

\begin{tabular}{lcccc} 
LBW $(<2500$ gram $)$ & $29(34 \%)$ & $157(13 \%)$ & $134(18.2 \%)$ & 0.0001 \\
VLBW $(<1500$ gram $)$ & $6(7 \%)$ & $39(3.3 \%)$ & $25(3.4 \%)$ & NS \\
IUGR & $2(2.4 \%)$ & $22(1.8 \%)$ & $38(5.2 \%)$ & 0.0001 \\
LGA & 0 & $7(0.6 \%)$ & $4(0.5 \%)$ & NS \\
PROM & $8(9.4 \%)$ & $67(5.6 \%)$ & $81(11 \%)$ & 0.0001 \\
$5^{\text {th }}$ minute Apgar score $<7$ & $6(7 \%)$ & $17(1.4 \%)$ & $28(3.8)$ & 0.04 \\
Fetal death & $3(3.5 \%)$ & $7(0.6 \%)$ & $9(1.2 \%)$ & 0.015 \\
Neonatal death & $2(2.4 \%)$ & $2(0.2 \%)$ & $2(0.3 \%)$ & 0.002 \\
Admission to NICU & $16(18.8 \%)$ & $114(9.5)$ & $114(15.5)$ & 0.0001 \\
\hline
\end{tabular}

LBW: low birth weight; VLBW: very low birth weight; IUGR: intrauterine growth restriction; PROM: premature rupture of membrane; LGA: large for gestational age; NICU: neonatal intensive care unit; $\mathrm{N}$ : non-significant

$\mathrm{N}$ : non-significant

TABLE 3. Adjusted OR for association between maternal age, and maternal and perinatal outcomes

\begin{tabular}{lccc}
\hline & \multicolumn{3}{c}{ Maternal age (years) } \\
\cline { 2 - 4 } Variables & $\leq 15$ Adjusted OR & $16-19$ Adjusted OR $20-34$ (ref) \\
\hline Preterm delivery $<37$ weeks & $2.69(1.62-4.45)^{* * *}$ & $1.18(0.92-1.52)$ & 1.0 \\
Early preterm delivery & $2.63\left(1.30-4.53^{* * *}\right.$ & $1.03(0.77-1.51)$ & 1.0 \\
$<34$ weeks & & & \\
LBW (<2500 g) & $1.26(0.61-2.61)$ & $0.52\left(0.36-0.76^{* *}\right.$ & 1.0 \\
IUGR & $0.61(0.14-2.6)$ & $0.43\left(0.26-0.76^{* *}\right.$ & 1.0 \\
Preeclampsia & $0.59(0.81-1.69)$ & $0.487(0.32-0.74)^{* *}$ & 1.0 \\
Gestational Diabetes & - & $0.11(0.03-0.5)^{* *}$ & 1 \\
PROM & $1.01(0.46-2.21)$ & $0.57\left(0.40-0.82^{* *}\right.$ & 1.0 \\
Anemia & $1.91(1.01-3.62)^{*}$ & $1.47(1.08-2.01)^{*}$ & 1.0 \\
$5^{\text {th }}$ minute Apgar score<7 & $1.81(0.39-8.35)$ & $0.47(0.16-1.34)$ & 1.0 \\
Fetal death & $4.94(1.15-21.27)^{*}$ & $0.80(0.27-2.39)$ & 1.0 \\
Neonatal death & $21.09\left(2.89-153.91^{* * *}\right.$ & $0.83(0.11-6.35)$ & 1.0 \\
Admission to NICU & $1.06(0.55-2.06)$ & $0.67(0.48-0.93)$ & 1.0 \\
\hline
\end{tabular}

LBW: low birth weight; IUGR: intrauterine growth restriction; PROM: premature rupture of membrane; NICU: neonatal intensive care unit

Logistic regression between adolescent mothers aged $\leq 15$ years, $16-19$ years and the adult reference group aged 20-34.

${ }^{*} \mathrm{p}<0.05,{ }^{*} \mathrm{p}<0.01, * * * \mathrm{p}<0.001$. 
risk of anemia than mothers aged 20-34 years. Considering other maternal morbidities, chorioamnionitis, endometritis, laceration at birth and postpartum hemorrhage were not different between adolescent and adult mothers.

\section{DISCUSSION}

The present study investigated the correlation between maternal age and the risk of adverse maternal and perinatal outcomes in our center. Our center accounts for approximately $10 \%$ of the total births in Istanbul, which is the biggest city in Turkey. This study demonstrated that our population had a high teenage birth rate, similar to most of the studies from developed and developing countries (24,25).

Younger maternal age is associated with being unmarried, primiparous and under-educated, alcohol/substance abuse, heavy smoking and inadequate prenatal care, which may lead to adverse pregnancy outcomes $(2,16-22)$. Young mothers may also be more likely to have a pregnancy due to sexual abuse compared with adult mothers, which could lead to an impaired stress response or to variable behaviors that increase the likelihood of preterm delivery (22). To evaluate the effect of younger maternal age on pregnancy outcomes, these confounding variables have to be considered. Our population was comprised of Muslim women. Teenage pregnancies were almost always desired and these women are married. Also, because of traditional and religious thoughts, alcohol or substance abuse is almost unheard of (26). Sexual abuse pregnancies constituted a very small portion of all adolescents in our center; we therefore excluded this population due to there more likely being an effect on pregnancy outcomes. Also, this study included only singleton primiparous women between teenage and adult groups due to possible effect of parity on pregnancy outcomes.

This study confirmed increased risk of prematurity in younger adolescent group after adjusting for confounding variables, similar to previous studies (3-16). Scholl et al. (17) explained the association between low gynecological age (conception within 2 years after menarche) and preterm delivery as insufficiency in maturity of the uterine and cervical blood supply may cause susceptibility young pregnant women to subclinical infection, prostaglandin production increase and a trend towards the increased incidence of preterm delivery. We did not include the incidence of genital tract infections. However, lower urinary tract infection, which was considered a reflection of genital tract infection, was found to be significantly higher in younger adolescents. The present study supported biological immaturity in the younger adolescent group with a higher incidence of PROM compared with older adolescents.
It was thought to be associated with higher rates of genitourinary infection. On the other hand, the relationship between preterm delivery and the low gynecological age $(<16$ years $)$ continued after adjustment for urinary tract infection, PROM and the other confounding variables. The other explanation of preterm delivery for younger adolescents, short cervix $(\leq 25 \mathrm{~mm})$ and small uterine volume may also be more common among younger mothers $(27,28)$.

This study also confirmed the higher risk of LBW among infants of younger adolescent mothers, as found in the most previous studies (4-10). However, in accordance with Vienne et al. (2), these associations were not significant after adjusting for confounding variables. The results of studies related to the association of teenage pregnancy and IUGR are contradictory $(11,12)$; in fact, some of them were not adjusted for confounding factors. We observed a lower incidence of intrauterine growth restriction in teenage pregnancy, especially in the older adolescent group. The disappearance of the higher risk of LBW among infants of adolescent mothers could be associated with lower rates of IUGR in the adolescent group compared with the adult group. Although it may be due to the small sample numbers, the present study showed an increased risk of intrauterine fetal deaths in pregnant young adolescents, consistent with other studies $(2,3,8,11,14)$ (adjusted OR: 4.94). On the contrary, some large population studies reported that fetal death was usually either unaffected or decreased in cases with younger maternal age $(3,4,13,15)$. Also, conflicting results were reported in previous investigations about neonatal mortality in adolescent pregnancy $(4,6,8-11,13,14)$. In our study, infants from younger adolescent mothers showed a higher risk of early neonatal death related to preterm delivery and LBW (adjusted OR: 21.09), although this may be due to the small sample numbers.

In accordance with the previous reports from either developed or developing countries, we found that adolescent mothers more frequently experienced anemia than adult mothers $(3-6,9,10)$. Iron requirements during adolescence significantly increase due to faster growth spurts and the start of menses (29). Moran emphasized that low iron stores before pregnancy in young women makes them more prone to iron deficiency in pregnancy and most cases had insufficient dietary intake (30). In agreement with other studies $(4,12)$, we found that gestational diabetes was lower in adolescent women. This supports the need for screening for gestational diabetes in young women with risk factors. Either increased (3-5) or decreased risks $(10,13)$ of preeclampsia have been reported in other studies. In addition, we found significantly lower incidence of preeclampsia amongst teenage mothers in accordance with Vienne et al. (2). In this study, adolescent mothers were more likely to have a vaginal delivery and had a lower caesarean 
delivery rate, as reported in many studies carried out to date $(4-8,13)$. The rate of CPD as an indication of cesarean delivery was observed to be lower in adolescent mothers. Higher vaginal delivery rates in adolescent mothers may be explained by favored myometrial function, greater elasticity of the connective tissue, lower compliance of the cervix and low birth weight babies $(31,32)$. The rate of episiotomy in our study was significantly higher among adolescent pregnancy, particularly among young adolescents. However, the rate of perineal tears did not differ between adolescent and adult pregnancies. Our center is a teaching hospital where most deliveries are carried out by residents and students in training. Episiotomy is usually performed against the risk of perineal tears in primiparous pregnancy. We therefore believe that this high episiotomy rate might have prevented perineal tears.

We acknowledge a number of limitations of our study because of the retrospective characteristic of the analysis. We could not assess some factors which are known to have an effect on adverse pregnancy outcomes, such as pre-pregnancy body mass index, weight gain during pregnancy, family income, employment and sexually transmitted disease. Furthermore, although the size of the cohort was appropriate, the younger adolescent and adult groups were not represented by optimal numbers of individuals. Therefore, some of the borderline associations could potentially reach significance in larger samples Also, our study reflects the population in one center and one country; therefore, our results may not apply to all populations.

In conclusion, the results of the present study confirm that adolescent pregnancy should be evaluated in two groups as young and older adolescents based on biological immaturity. Young adolescent mothers were more likely to deliver preterm and experience a high risk of fetal and neonatal death. Therefore, young adolescent pregnancies, which have adverse perinatal outcomes, need further attention and investigation. Our mission should be aimed at reducing the numbers of adolescent pregnancies and providing adequate antenatal care for young pregnant women.

Ethics Committee Approval: Ethics committee approval was received for this study from the local ethics committee. $(19.12 .2011 / 19890)$

Informed Consent: Written informed consent was obtained from the parents of the patients who participated in this study.

Peer-review: Externally peer-reviewed.

Author contributions: Concept - O.D.; Design - O.D., E.Y., Ö.T.; Supervision - O.D., P.K. ; Resource - O.D.; Materials - S.S., Z.N.D.;
Data Collection and/or Processing - A.A., D.M., R.A.; Analysis and/ or Interpretation - P.K., R.A.; Literature Search - O.D., E.E.; Writing - O.D.; Critical Reviews - N.T., E.Y., Ö.T.

Conflict of Interest: No conflict of interest was declared by the authors.

Financial Disclosure: The authors declared that this study has received no financial support.

\section{REFERENCES}

1. World Health Organization. Making Pregnancy Safer: Adolescent Pregnancy. 2011.

2. de Vienne CM, Creveuil C, Dreyfus M. Does young maternal age increase the risk of adverse obstetric, fetal and neonatal outcomes: a cohort study. Eur J Obstet Gynecol Reprod Biol 2009;147:151-6. [CrossRef]

3. Pergialiotis V, Vlachos DG, Gkioka E, Tsotra K, Papantoniou N, Vlachos GD. Teenage pregnancy antenatal and perinatal morbidity: Results from a tertiary centre in Greece. J Obstet Gynaecol 2014;19:1-5.

4. Conde-Agudelo A, Belizán JM, Lammers C. Maternal-perinatal morbidity and mortality associated with adolescent pregnancy in Latin America: Cross-sectional study. Am J Obstet Gynecol 2005;192:342-9. [CrossRef]

5. Ganchimeg T, Mori R, Ota E, Koyanagi A, Gilmour S, Shibuya $\mathrm{K}$, et al. Maternal and perinatal outcomes among nulliparous adolescents in low- and middle-income countries: a multi-country study. BJOG 2013;120:1622-30. [CrossRef]

6. Ganchimeg T, Ota E, Morisaki N, Laopaiboon M, Lumbiganon P, Zhang J, et al; WHO Multicountry Survey on Maternal Newborn Health Research Network. WHO Multicountry Survey on Maternal Newborn Health Research Network. Pregnancy and childbirth outcomes among adolescent mothers: a World Health Organization multicountry study. BJOG 2014;121:40-8. [CrossRef]

7. Thaithae S, Thato R. Obstetric and perinatal outcomes of teenage pregnancies in Thailand. J Pediatr Adolesc Gynecol 2011;24:342-6. [CrossRef]

8. Shrim A, Ates S, Mallozzi A, Brown R, Ponette V, Levin I, et al. Is young maternal age really a risk factor for adverse pregnancy outcome in a canadian tertiary referral hospital? J Pediatr Adolesc Gynecol 2011;24:218-22. [CrossRef]

9. Gibbs CM, Wendt A, Peters S, Hogue CJ. The impact of early age at first childbirth on maternal and infant health. Paediatr Perinat Epidemiol 2012;26:259-84. [CrossRef]

10. Bildircin FD, Kurtoglu E, Kokcu A, Işik Y, Ozkarci M, Kuruoglu S. Comparison of perinatal outcome between adolescent and adult pregnancies. J Matern Fetal Neonatal Med 2014;27:829-32. [CrossRef]

11. Malabarey OT, Balayla J, Klam SL, Shrim A, Abenhaim HA. Pregnancies in young adolescent mothers: a population-ba- 
sed study on 37 million births. J Pediatr Adolesc Gynecol 2012;25:98-102. [CrossRef]

12. Figuerêdo ED, Lamy Filho F, Lamy ZC, Silva AA. Maternal age and adverse perinatal outcomes in a birth cohort (BRISA) from a Northeastern Brazilian city. Rev Bras Ginecol Obstet 2014;36:562-8. [CrossRef]

13. Gupta N, Kiran U, Bhal K. Teenage pregnancies: obstetric characteristics and outcome. Eur J Obstet Gynecol Reprod Biol 2008;137:165-71. [CrossRef]

14. Fouelifack FY, Tameh TY, Mbong EN, Nana PN, Fouedjio JH, Fouogue JT, et al. Outcome of deliveries among adolescent girls at the Yaoundé central hospital. BMC Pregnancy Childbirth 2014;14:102. [CrossRef]

15. Haldre K, Rahu K, Karro H, Rahu M. Is a poor pregnancy outcome related to young maternal age? A study of teenagers in Estonia during the period of major socio-economic changes (from 1992 to 2002). Eur J Obstet Gynecol Reprod Biol 2007;131:45-51. [CrossRef]

16. Lubarsky SL, Schiff E, Friedman SA, Mercer BM, Sibai BM. Obstetric characteristics among nulliparas under age 15. Obstet Gynecol 1994;84:365-8.

17. Scholl TO, Hediger ML, Salmon RW, Belsky DH, Ances IG. Association between low gynaecological age and preterm birth. Paediatr Perinat Epidemiol 1989;3:357-66. [CrossRef]

18. Scholl TO, Hediger ML, Schall JI, Khoo CS, Fischer RL. Maternal growth during pregnancy and the competition for nutrients. Am J Clin Nutr 1994;60:183-8.

19. Chen XK, Wen SW, Fleming N. Teenage pregnancy and adverse birth outcomes: a large population based retrospective cohort study. Int J Epidemiol 2007;36:368. [CrossRef]

20. Yoder BA, Young MK. Neonatal outcomes of teenage pregnancy in a military population. Obstet Gynecol 1997;90:500-6. [CrossRef]

21. Strobino DM, Ensminger ME, Kim YJ, Nanda J. Mechanisms for maternal age differences in birth weight. Am J Epidemiol 1995;142:504-14.
22. Stevens-Simon C, Beach RK, McGregor JA. Does incomplete growth and development predispose teenagers to preterm delivery? A template for research. J Perinatol 2002;22:31523. [CrossRef]

23. Hadlock FP, Harrist RB, Sharman RS, Deter RL, Park SK. Estimation of fetal weight with the use of head, body, and femur measurements--a prospective study. Am J Obstet Gynecol 1985;151:333-7. [CrossRef]

24. Ventura SJ, Abma JC, Mosher WD, Henshaw SK. Estimated pregnancy rates by outcome for the United States, 1990-2004. Natl Vital Stat Rep 2008;56:1-25-8.

25. UNICEF. A league table of teenage births in rich nations. Florence (Italy): UNICEF Innocenti Research Centre; 2001.

26. Geist RR, Beyth Y, Shashar D, Beller U, Samueloff A. Perinatal outcome of teenage pregnancies in a selected group of patients. J Pediatr Adolesc Gynecol 2006;19:189-93. [CrossRef]

27. Da Costa AG, Mauad F, Ferreira AC, Spara P, Mauad FM. Uterine volume in adolescents. Ultrasound Med Biol 2004;30:7-10. [CrossRef]

28. Stevens-Simon C, Barrett J, McGregor JA, French J, Persutte W. Short cervix: a cause of preterm delivery in young adolescents? J Matern Fetal Med 2000;9:342-7. [CrossRef]

29. Beard JL. Iron requirements in adolescent females. J Nutr 2000;130:440S-2S.

30. Moran VH. Nutritional status in pregnant adolescents: a systematic review of biochemical markers. Matern Child Nutr 2007;3:74-93. [CrossRef]

31. Jolly MC, Sebire N, Harris J, Robinson S, Regan L. Obstetric risks of pregnancy in women less than 18 years old. Obstet Gynecol 2000;96:962-6. [CrossRef]

32. Ziadeh S. Obstetric outcome of teenage pregnancies in North Jordan. Arch Gynecol Obstet 2001;265:26-9. [CrossRef] 